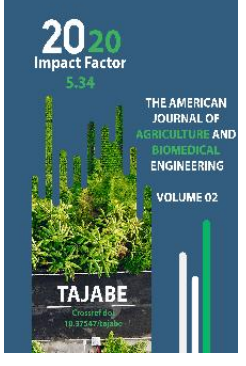

Journal Website: http://usajournalshub.c om/index,php/tajabe

Copyright: Original content from this work may be used under the terms of the creative commons attributes 4.0 licence.

\section{Inheritance Of Output And Fiber Length In Genotypically Remote Medium Fiber F1 Cotton Plants}

Kodirova M. R. Institute Of Genetics And Experimental Plant Biology, Academy Of Sciences Of The Republic Of Uzbekistan, Tashkent, Uzbekistan

Kahharov I.T. Institute Of Genetics And Experimental Plant Biology, Academy Of Sciences Of The Republic Of Uzbekistan, Tashkent, Uzbekistan

\title{
ABSTRACT
}

This article provides data on the inheritance of fiber yield and fiber length in first generation hybrid forms derived from genotypically different forms of G.hirsitum $L$ species medium fiber cotton. The obtained results showed that in hybrids F1 dominance of one of the parent forms and intermediate inhe $\neg$ ritance by the characteristics of yield and length of fibre is manifested in hybrids of forms with different ge $n$ notype, with high and medium index, and inheritance by the type of positive superdomination, i.e. positive heterosis - in hybrids of forms with medium and high index.

\section{KEYWORDS}

Cotton, fiber yield and length, inheritance, overdominance, heterosis.

\section{INTRODUCTION}

Improving the quality of cotton fiber of the species G.hirsitum L., which accounts for $95 \%$ of all sown areas occupied by this crop, is one of the most important tasks of the selection prongrams of cotton producing states. Today, cotton producing countries of the world, pay special attention to the creation of fruitful cotton varieties with a high yield of fiber, 
resistant to diseases and pests and unfavorable environmental factors that meet modern production requirements and increase their purity.

Recently, scientific research has been carried out to create cotton varieties that fully meet the requirements of the industry, which is developing at an accelerated pace. Determination of the patterns of inheritance and variability of economically valuable traits of cotton, the manife $n$ station of heterosis, as well as the determination of its preservation in hybrid populations with intraspecific, genotypically distant hybridization of cotton is important for the continuous crea-tion of effective varieties with a high hereditary potential that have advantages in terms of com pplex traits over standard varieties.

Fiber yield is one of the most important genetic and economic traits, inherited depending on the seed mass and fiber index.

About 27 million tons of fiber is produced from cotton per year, which is estimated at \$ 500 billion per year. It should be noted that 3.5 million tons of cotton are grown in Uzbekistan per year, of which comes a \$900-1200 million profit.

\section{RESEARCH OBJECTIVE}

One of the urgent tasks of cotton growing is the creation of new varrieties with unique characteristics and properties, early ripening, with a high yield and quality of fiber, highyielding, resistant to diseases and pests and meeting the quality requirements, as well as determining the inheritance and variability of morpho-economic characteristics in hybrid pop ulations, isolation of plants with enriched genotypes during hybridization of genotypically dif $\neg$ ferent forms of cotton of the species $G$ hirsutum $L$.

\section{MATERIAL AND RESEARCH METHODS}

Scientific research was carried out at the experimental station of Institute of Genetics and Experimental Biology of Plants of the Academy of Sciences of the Republic of Uzbekistan, loncated in Zangiata district, Tashkent region. This territory is located on the upper route of the Chirchik River, at an altitude of 398 meters above sea level. The number of sunny days is $175-185$, and the frostfree period is 210 days. Field sowing was carried out in the third decade of April. Mineral fertilizers were applied before sowing, during sowing, as well as 3 times by feeding during the growing season (the first feeding was in the initial phase of budding, the second was during budding, and the third was in the flowering-ripening phase).

For scientific research, the parental forms of cotton varieties Namangan-77, 75007-11 (Australia), Kupaysin, Kelajak, UzFA-705 and line $L-500$ of medium fiber cotton of the species G. hirsutum L. and their hybrids F1, F2, F3 obtained with diallelic family crosses, new lines, as well as the L-500 line (currently UzFA713 variety).

Classical methods of genetics and cotton selection, various genotypic forms crossing me $\neg$ thods, as well as comparative morphology and phenological observations, hybridological and genetic-statistical analysis were used. All plants of the studied varieties and their F1, F2, F3 gen-erations, families and lines were grown under the same conditions, adhering to randomization, hybridological and statistical variance analyzes were applied. The data were statistically processed according to B.P. Dospekhov (1985). In F1 plants, the degree of dominance (hp) was determined by the Wright formula (Beil and Atkins, 1965). 


$$
\mathrm{Hp}=\frac{\mathrm{MP}-\mathrm{F} 1}{\mathrm{P}-\mathrm{MP}}
$$

Here, hp - dominance coefficient;

MP - average value of parental forms;

F1 - hybrid index;

$\mathrm{P}$ - best parent index.

In the first hybrid generation, the inheritance of traits is expressed in the following order:

$$
\begin{gathered}
\mathrm{hp}=0 \text { - dominance case was not observed; } \\
0<\mathrm{hp}<1 \text { - partial dominance; } \\
\mathrm{hp}=1 \text { - complete dominance; } \\
\text { hp }>1 \text { - overdominance or heterosis; }
\end{gathered}
$$

\section{RESEARCH RESULTS AND DISCUSSION}

In our experiment, we studied parental forms and fiber yield rates on $\mathrm{F} 1$ plants. According to analyzes of the indices of the fiber yield trait, the studied parental forms were divided into 3 groups of high, medium and low yield. The first group consisted of 75007-11 (41.3\%) and Namangan-77 (39.4\%) varieties with a high fiber yield, the second group consisted of Kelajak (38.8\%) and Kupaysin (38.1\%) varieties, the third group consisted of UzFA-705 (37.4\%) and UzFA-713 (36.0\%) varieties with a relatively low output fiber (Table-1.).

The highest fiber yield was observed in $F_{1}$ UzFA-713 $x$ Kupaisin (42.0\%), 75007-11 $x$ Kupaisin (40.2\%) and 75007-11 x UzFA-705 (40.7\%), Kelazhak x Kupaysin (39.8\%), Kupaysin x Kelajak (39.5\%), Kelajak x UzFA-705 (39.5\%), Namangan-77 x UzFA-713 (39.8\%), Kupaisin $x$
UzFA-705 (39.5\%), the average index for plants Kelajak x Kupaysin (39.8\%), Kupaysin x Kelajak (39.5\%), Kelajak x UzFA-705 (39.5\%), Namangan-77 x UzFA-713 (39.8\%), Kupaysin $x$ UzFA-705 (39.5\%), UzFA-705 x Kupaisin (39.0 \%), UzFA-705 x 75007-11 (39.8\%), UzFA-705 x Kelajak (38.4\%), UzFA-705 x Namangan-77 (38.6\%), UzFA-713 x UzFA-705 (38.0\%), 75007-11 x Namangan-77 (38.1\%), 75007- 11 x UzFA-713 (38.9\%), a relatively low yield was observed in hybrids Kelajak x Namangan-77 (36.6\%), Kelajak x 75007-1 (36.7\%), Namangan-77 x Kupaisin (36, 8\%), Namangan-77 x 75007-11 (37.5\%), Kupaysin x Namangan-77 (37.3\%), Kupaisin x UzFA-713 (33.4\%), Kupaisin x 7500711 (37.6\%), UzFA-705 x UzFA-713 (35.7\%), UzFA$713 \times$ Kelajak (37.0\%), UzFA-713 x Namangan-77 (37.8\%), UzFA-713 x 75007-11 (36.9\%), 75007-11 x Kelajak (37.9\%). 
Table 1

Fiber Yield Inheritance in F1 Plants

\begin{tabular}{|c|c|c|c|c|c|c|c|}
\hline \multicolumn{2}{|l|}{ q } & $\frac{\frac{\pi}{\pi}}{\frac{\pi}{\pi}}$ & 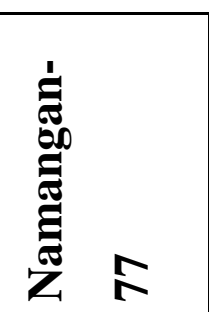 & 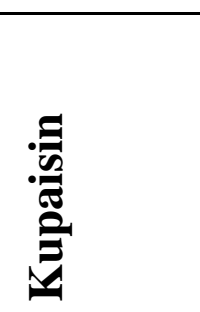 & 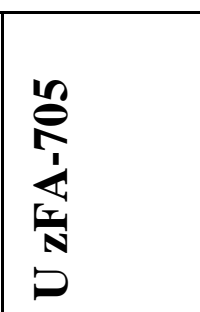 & $\frac{n}{2}$ & $\underset{7}{7}$ \\
\hline \multirow[t]{3}{*}{ Kelajak } & $\mathrm{X} \pm \mathrm{Sx}$ & $38,8 \pm 0,3$ & $36,6 \pm 0,4$ & $39,8 \pm 0,8$ & $39,5 \pm 0,6$ & $38,5 \pm 0,5$ & $36,7 \pm 0,6$ \\
\hline & 6 & 0,6 & 0,9 & 1,4 & 0,9 & 0,8 & 1,0 \\
\hline & hp & - & $-1,2$ & 3,5 & 4,5 & 0,7 & $-2,5$ \\
\hline \multirow{3}{*}{$\begin{array}{l}\text { Namangan- } \\
77\end{array}$} & $\mathrm{X} \pm \mathrm{Sx}$ & $38,3 \pm 0,6$ & $39,4 \pm 0,4$ & $36,8 \pm 0,6$ & $38,4 \pm 0,5$ & $39,8 \pm 0,7$ & $37,5 \pm 0,5$ \\
\hline & $\sigma$ & 1,1 & 0,7 & 1,2 & 0,9 & 1,4 & 0,8 \\
\hline & hp & 0,7 & - & $-2,7$ & 0,5 & 1,2 & $-3,8$ \\
\hline \multirow[t]{3}{*}{ Kupaisin } & $\mathrm{X} \pm \mathrm{Sx}$ & $39,5 \pm 0,7$ & $37,3 \pm 0,8$ & $38,1 \pm 0,5$ & $39,5 \pm 0,4$ & $33,4 \pm 0,7$ & $37,6 \pm 0,6$ \\
\hline & 6 & 0,9 & 1,2 & 1,0 & 0,8 & 1,1 & 1,2 \\
\hline & $\mathrm{hp}$ & 2,7 & $-1,7$ & - & 2,4 & $-3,2$ & $-1,3$ \\
\hline \multirow[t]{3}{*}{ U zFA-705 } & $\mathrm{X} \pm \mathrm{Sx}$ & $38,4 \pm 0,7$ & $38,6 \pm 1,0$ & $39,0 \pm 0,4$ & $37,4 \pm 0,5$ & $35,7 \pm 1,0$ & $39,8 \pm 0,4$ \\
\hline & $\sigma$ & 1,3 & 1,6 & 0,7 & 0,8 & 1,0 & 0,9 \\
\hline & hp & 0,9 & $-0,6$ & 2,1 & - & $-1,3$ & 0,4 \\
\hline \multirow[t]{3}{*}{ U zFA-7 13} & $\mathrm{X} \pm \mathrm{Sx}$ & $37,0 \pm 0,6$ & $37,8 \pm 0,8$ & $42,0 \pm 0,7$ & $38,0 \pm 0,6$ & $36,0 \pm 0,5$ & $36,9 \pm 0,7$ \\
\hline & $\sigma$ & 0,9 & 1,6 & 1,1 & 0,9 & 0,7 & 1,5 \\
\hline & hp & $-0,2$ & 0,7 & 4,5 & 1,4 & - & $-0,6$ \\
\hline \multirow[t]{3}{*}{$75007-11$} & $\mathrm{X} \pm \mathrm{Sx}$ & $37,9 \pm 0,9$ & $38,1 \pm 0,4$ & $40,2 \pm 0,5$ & $40,7 \pm 0,7$ & $38,9 \pm 0,6$ & $41,3 \pm 0,7$ \\
\hline & $\sigma$ & 1,8 & 0,9 & 0,8 & 1,5 & 1,2 & 1,5 \\
\hline & hp & $-1,6$ & $-2,9$ & 0,4 & 0,6 & 0,6 & - \\
\hline
\end{tabular}


According to the fiber yield in F1 plants obtained by diallelic crossing, in 5 out of 30 com $\neg$ binations, the dominance of the paternal or maternal form was observed, in 12 combinations an intermediate degree of dominance with a deviation to the paternal or maternal forms, in 13 com $\neg$ binations, positive or negative overdominance. In terms of fiber yield in the studied F1 plants, complete dominance of the paternal or maternal form was observed in combinations Kelajak $x$ Namangan-77 (hp=-1.2), Namangan-77 x UzFA713 (hp=1.2), Kupaisin x 75007-11 (hp=-1.3) and UzFA-705 x UzFA-713 (hp=-1.3) in plants with sharply differing indices.

And an intermediate degree of dominance of the average index in F1 plants was ob sserved in $\mathrm{F} 1$ plants from forms with average indices Kelajak $x$ UzFA-713 $(\mathrm{hp}=0.7)$, UzFA-713 $\mathrm{x}$ Kelajak (hp=-0.2), UzFA-713 x Namangan-77 (hp=0.7), UzFA-713 x 75007-11 (hp=-0.6), 75007-11 x Kupaisin (hp=0.4), 75007-11 x UzFA$705(\mathrm{hp}=0.6)$ and 75007-11 x UzFA-713 (hp= $0.6)$.

It should be noted that the heredity of the fiber yield trait in F1 plants depends on ge $\neg$ notype and index of parental varieties, and all types of inheritance have been found. The presence of reciprocal differences in 9 direct and reverse combinations according to the fiber yield showed the participation of cytoplasmic genes in the hereditary control of the trait along with nuclear genes, as well as the absence of reciprocal differences in 9 direct and reverse com-binations indicates the heredity of the trait mainly under the influence of nuclear genes.

Thus, in F1 plants, the predominance of the paternal or maternal form in terms of fiber yield is manifested depending on their index and origin. Since the degree of intermediate inherit ance of fiber yield in F1 plants depends on the contrast and geographical distance of the index of the initial-parental forms. The positive degree of inheritance, positive heterosis in terms of fiber yield in F1 plants was manifested depending on the genotypic proximity and geographic distance of their parental forms. The negative degree of dominance, the manifestation of negative hetero sis based on fiber yield, in addition to their genotypic and geographic remoteness, depended on the contrast of indices of parental forms.

Data such as those obtained as a result of our research were obtained as a result of a number of others $[1 ; 89-91-\mathrm{C}]$ researches that in complex F1 cotton plants, the degree of overdominance was observed in terms of early maturity and fiber yield.

In the experiments carried out by V.A. Avtonomov [2; 36-41-C], F1 plants, maternal and paired lines, as well as cultivars were studied against a deliberately infected gummosis background, as a result of which the opposite effect of factors on the yield and fiber length was not ob $\urcorner$ served. When genetic analysis combined with high rates of plants $F$, is detected dominance is, the parent form.

In the studies of O. J. Jalilov [3; 13-14-C], the manifestation of heterosis in F1 plants was observed when varieties with the same or close to each other in terms of fiber yield were crossed. In many hybrid combinations, a weaker reciprocal difference is found. This means that cytoplasmic genes are also involved to some extent in the genetic control of the fiber yield trait in F1 plants . 
Fiber length is one of the most important factors in determining fiber quality.

The main goal and challenge of all breeders in the world is to increase cotton yields and improve fiber quality. Therefore, the study of valuable traits and properties of cotton is one of the most important objectives in cotton growing.

Taking this into account, in our experiment, we studied indices of fiber length trait in parental varieties and their F1 plants.

According to analysis of fiber length, we divided the studied varieties into 3 groups: long, medium and short. The first group is the Kupaysin variety $(35,2 \mathrm{~mm})$ with long fiber, the second is the Kelazhak variety $(34,5 \mathrm{~mm})$ and UzFA-705 (34,5 mm) with medium fiber, the third group is the relatively low variety 75007-11 (33,9 mm), UzFA-713 (33,9 mm) and Namangan-77 (33,6 mm) (table-2).

The highest fiber length was observed in plants F1 Kelajak x Namangan-77 (35,4 mm), Kelajak x UzFA-705 (36,3 mm), Namangan-77 x UzFA-713 (36, $2 \mathrm{~mm})$, Kupaisin $x$ UzFA-705 $(36,1 \mathrm{~mm})$ UzFA-Kupaysin $705 \times(35,7 \mathrm{~mm}) 77$ $x$ Namangan UzFA-705 (35,8 mm), va-UzFA $705 \times$ Namangan-77 (35,4 mm), average index for plants Namangan-77 x Kupaysin (34,5 mm),
Kupaisin $x$ Kelazhak (34,2 mm), Kupaisin $x$ UzFA-713 (34,2 mm) and UzFA-713 x Kuาpaisin (34,2 mm), Kupaisin x 75007-11 (34,2 mm), UzFA-705 x UzFA-713 (34,3 mm), 75007-11 x Kelajak (34,4 mm), a relatively low index was observed in hybrids Kelajak $x$ Kupaysin $(32,4$ $\mathrm{mm})$, Kelajak x UzFA-713 (33,0 mm) and UzFA$705 \times$ Kelajak (33,1 mm), Kelajak x 75007-1 (32,3 mm), Namangan-77 x Kelajak (33,2 mm), Namangan-77 x 75007-11 (33,8 mm) and 75007$11 \times$ Namangan-77 (33,1 mm), Kupaysin $x$ Namangan-77 (33,5 mm), UzFA-705 x 75007-11 $(33,8 \mathrm{~mm})$ and 75007-11 x UzFA-705 (33,2 $\mathrm{mm}$ ), UzFA-713 x Kelajak (33,6 mm), UzFA- 713 $x$ Namangan-77 (33,0 mm), UzFA-713 x UzFA705 (33,0 mm), UzFA-713 x 75007-11 (32,4 mm) and 75007-11 x UzFA-713 (32, $1 \mathrm{~mm}), 75007-11 \mathrm{x}$ Kupaysin (32,5 mm).

As for the fiber length, the dominance of paternal or maternal form was observed in 4 out of 30 combinations in F1 plants obtained by diallel crossing; in 6 combinations, the intermediate dominance of paternal or maternal forms; in 20 combinations - positive or negative overdominance. In terms of fiber length in F1 plants, the dominance of paternal or maternal form was observed in Namangan$77 \times$ Kupaisin ( $h p=1.1)$, Kupaisin x Namangan77 (hp=-1.1) and UzFA-705 x 75007-11 (hp=-1.2) with sharply differing indices. 
Table 2

Fiber length inheritance in plants F1 (mm)

\begin{tabular}{|c|c|c|c|c|c|c|c|}
\hline \multicolumn{2}{|l|}{ q } & $\frac{\sqrt[n]{\pi}}{\frac{\pi}{\pi}}$ & 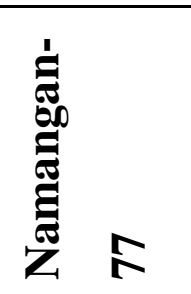 & 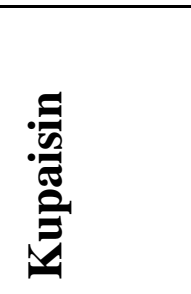 & 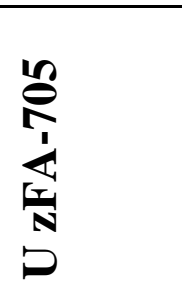 & 离 & 궁 \\
\hline \multirow[t]{3}{*}{ Kelajak } & $\mathrm{X} \pm \mathrm{Sx}$ & $34,5 \pm 0,4$ & $35,4 \pm 0,6$ & $32,4 \pm 0,8$ & $36,3 \pm 0,7$ & $33,0 \pm 0,5$ & $32,3 \pm 06$ \\
\hline & 6 & 0,6 & 1,1 & 1,6 & 1,2 & 0,8 & 0,9 \\
\hline & $\mathrm{hp}$ & - & 1,7 & $-6,0$ & 2,4 & $-4,0$ & $-6,3$ \\
\hline \multirow[t]{3}{*}{ Namangan-77 } & $\mathrm{X} \pm \mathrm{Sx}$ & $33,2 \pm 0,4$ & $33,6 \pm 0,5$ & $34,5 \pm 0,7$ & $35,8 \pm 0,6$ & $36,2 \pm 0,8$ & $33,8 \pm 0,5$ \\
\hline & 6 & 0,8 & 1,1 & 0,6 & 0,9 & 1,2 & 0,7 \\
\hline & $\mathrm{hp}$ & $-1,6$ & - & 1,1 & 5,2 & 4,7 & 0,9 \\
\hline \multirow[t]{3}{*}{ Kupaisin } & $\mathrm{X} \pm \mathrm{Sx}$ & $34,2 \pm 0,6$ & $33,5 \pm 0,7$ & $35,2 \pm 0,4$ & $36,1 \pm 0,5$ & $34,2 \pm 0,8$ & $34,2 \pm 0,6$ \\
\hline & 6 & 0,8 & $-1,3$ & 0,8 & 0,9 & 1,2 & 1,0 \\
\hline & $\mathrm{hp}$ & $-1,5$ & $-1,1$ & - & 3,1 & 0,4 & 0,4 \\
\hline \multirow[t]{3}{*}{ U zFA-705 } & $\mathrm{X} \pm \mathrm{Sx}$ & $33,1 \pm 0,7$ & $35,4 \pm 0,6$ & $35,7 \pm 0,7$ & $34,5 \pm 0,4$ & $34,3 \pm 0,5$ & $33,8 \pm 0,8$ \\
\hline & 6 & 1,2 & 0,9 & 1,1 & 0,7 & 0,8 & 1,3 \\
\hline & $\mathrm{hp}$ & $-1,4$ & 4,9 & 2,6 & - & $-0,3$ & $-1,2$ \\
\hline \multirow[t]{3}{*}{ U zFA-7 13} & $\mathrm{X} \pm \mathrm{Sx}$ & $33,6 \pm 0,6$ & $33,0 \pm 0,7$ & $34,2 \pm 0,5$ & $33,0 \pm 0,7$ & $33,9 \pm 0,6$ & $32,4 \pm 0,5$ \\
\hline & 6 & 0,9 & 1,1 & 0,7 & 1,3 & 0,8 & 1,0 \\
\hline & $\mathrm{hp}$ & $-2,0$ & $-3,5$ & 0,4 & $-1,9$ & - & $-1,5$ \\
\hline \multirow[t]{3}{*}{$75007-11$} & $\mathrm{X} \pm \mathrm{Sx}$ & $34,4 \pm 0,6$ & $33,1 \pm 0,3$ & $32,5 \pm 0,4$ & $33,2 \pm 0,5$ & $32,1 \pm 0,3$ & $33,9 \pm 0,4$ \\
\hline & 6 & 1,2 & 0,6 & 0,9 & 1,0 & 0,7 & 0,9 \\
\hline & hp & 0,6 & $-3,0$ & 2,8 & $-1,8$ & $-1,8$ & - \\
\hline
\end{tabular}

An intermediate degree of dominance of the average index was observed in plants $F 1$ Namangan-77 x 75007-11 (hp = 0.9), Kupaisin $x$ UzFA-713 (hp = 0.4), Kupaisin $\times 75007-11(\mathrm{hp}=$ 0.4), UzFA-705 x UzFA-713 (hp = -0.3), UzFA$713 \times$ Kupaisin $(\mathrm{hp}=0.4)$ and 75007-11 $\times$ Kelajak (hp = 0.6). On the basis of fiber length, positive overdominance was observed in plants with different genotypes and indices Kelajak x Namangan-77 (hp = 1.7), Kelajak $x$ UzFA-705 (hp = 2.4), with average indices Namangan-77 x UzFA-705 (hp = 5.2) and UzFA$705 \times$ Kupaysin $(\mathrm{hp}=2.6)$, Namangan-77 $\mathrm{x}$ UzFA-713 (hp = 4.7), Kupaisin x UzFA-705 (hp = 3.1) and UzFA -705 x Namangan-77 (hp = 4.9) and $75007-11 \times$ Kupaysin $(\mathrm{hp}=2.8)$, and 
negative overdominance was observed in Kelajak x Kupaisin (hp = -6.0), Namangan-77 x Kelajak (hp=-1.6), Kupaysin $x$ Kelajak ( $h p=-$ 1.5), UzFA-705 $x$ Kelajak (hp $=-1.4$ ), Kelajak $x$ UzFA-713 (hp = -4.0) and UzFA -713 x Kelajak $(\mathrm{hp}=-2.0)$, Kelajak x 75007-11 (hp = -6.3), UzFA$713 \times$ Namangan $-77(\mathrm{hp}=-3.5)$, UzFA-713 $\mathrm{x}$ UzFA-705 (hp = -1.9), UzFA-713 x 75007-11 (hp = -1.5), 75007-11 x Kupaisin (hp = -3.0), 75007-11 x Namangan-77 ( $h p=-3.0), 75007-11 \times$ UzFA-705 (hp =-1.8) and 75007-11 x UzFA-713 (hp = -1.8).

It should be noted that the inheritance of fiber length in $\mathrm{F} 1$ plants depends on the geno 7 type and indices of the parent varieties, and all degrees of inheritance are observed.

By fiber length, except for the combinations Kupaysin $x$ UzFA-705 and UzFA-705 $x$ Kupaisin, Namangan-77 x UzFA-705 and UzFA-705 $x$ Namangan-77, Kupaisin x UzFA-713 and UzFA$713 \times$ Kupaisin, Kelajak x UzFA- 705 and UzFA$705 \times$ Kelajak, Namangan-77 x 75007-11 and 75007-11 x Namangan-77, UzFA-705 x 75007-11 and 75007-11 x UzFA-705, UzFA-713 x 75007-11 and 75007- $11 \times$ UzFA-713, a reciprocal difference was observed in all forward and reverse hybrids, which indicates the participation of cytoplasmic genes in most cases of hereditary control of the trait along with nuclear genes.

Thus, the dominance of one of the parental forms in terms of fiber length in F1 plants is manifested in hybrids by sharply distinguishing characteristics of the forms. An intermediate inheritance of fiber length was observed in hybrids of genotypically close and geographically distant forms. Positive overdominance in terms of fiber length, positive heterosis was manifested in hybrids with different genotypes and geographically distant forms. Negative overdominance based on fiber length, that is, negative heterosis was manifested in hybrids with different genortypes and characteristics, as well as geographically distant forms. Thus, in F1 plants fiber length, mainly negative and positive overdominance was observed. Fiber length in F1 plants is regulated mainly by dominant genes, which has also been proven by our research. It is important to note that our data, that is, the overdominance of the fiber length, confirm the literature data $[4 ; 92-96-C],[5 ; 72-$ 74-C], [6;21-C], [7;46-47-C].

\section{CONCLUSION}

Thus, in F1 hybrids, the dominance of one of the parental forms and intermediate inheritance in terms of yield and fiber length is manifested in hybrids of forms with different genortypes, with high and medium rates, while inheritance is a type of positive overdominance, i.e. positive heterosis - in hybrids of forms with medium and high rates.

\section{REFERENCES}

1. Amanturdiev B. Inheritance and correlation of fiber length with other economically valuanble traits of cotton // Abstract. Ph.D. diss. T. 1971 , - S. 21.

2. Egamberdiev S.A. With korospelost interline and sortolineynyh cotton hybrids and other crops: Proceedings of the international scientific conference. T. 2005 , - S. 89-91.

3. Avtonomov V.A. Variability, inheritance characteristics in geographically distant hybr-ids F1 - F2 cotton G.hirsutum L .// State of selection and seed production of cotton and prospects for its development: Mat. int . scientific . conf. - Tashkent, 2006, - B. 36-41.

4. Jalilov O. J. Breeding of early ripening fruitful varieties of cotton with highquality finber// Rep..Acad. of Siences of UzSSR.- 1976 .- No. 3, - P.13-14 
5. Kimsanboev O.Kh. Variability, inheritance of traits in F1 -F2 hybrids with wild and ruderal forms of cotton//Condition of selection and seed production of cotton and prospects for its development. Mat . int . scientific . conf. - Tashkent, 2006 , - S. 92-96.

6. Combination of rapid maturation trait in interspecific hybrids// Mat . int . scientific . conf. "Evolutionary and breeding aspects of rapid maturation and flexibility of cotton and other agricultural crops" dedicated to the 95th anniversary of Academician S.S. Sodikov. T. 2005, p. 72-74.

7. Senoedov V.P. Inheritance of wilt resistance during intraspecific and interspecific hybridization of cotton// Rep..Acad. of Siences of UzSSR. 1986. No. 4, - S.46-47. 